\title{
A Dumb-Bell Shaped Damper with Magnetic Absorber using Ferrofluids
}

\author{
R.Karthick, P.Meenalochini, A.Manoj Prabaharan, P.Selvaprasanth, M.Sheik Dawood
}

\begin{abstract}
Damping devices are made up of ferrofluids which aid in strong magnetization and contribute greatly to minimizing magnetic vibrations. The most important and traditional applications of damping devices are used by ferrofluids and Nano magnetic materials. The combined effect of damping devices and ferrofluid materials show improved vibration minimization ratio. Here, it is observed that the basic damping device with ferrofluid materials consists of isolators, dampers, and absorbers. Moreover, novel dynamic isolation with absorption techniques is introduced in this paper. To obtain improved performance and efficiency of damping devices the use of isolators and vibration absorbers is suggested.
\end{abstract}

Keywords: Dynamic damping applications, ferrofluids, vibration isolator and absorber.

\section{INTRODUCTION}

Advanced nano magnetic fluid material is popularly known as ferrofluids[1]. The fundamental advantage of choosing ferrofluid is to act with both homogeneous and heterogeneous properties. A magnetite is a particle extracted from ferrofluid which exhibits nonmagnetic fluid with mono domain suspension [2].

Steve Papell introduced stable ferrofluid which controls the environment with microgravity [3] in 19th century. Particularly, Rabinow introduced magnetorheological (MR) which fluid is a different from of ferrofluid [4] in 1948. Most of the automotive and biomedical applications MR fluid plays an import role [5].

The iron particles such as magnetite and hematite with liquid in the size of nanometers, ferrofluids are manufactured. The chemical compositions for ferrofluids are in the range of magnetic solids-5\%, surfactant of $10 \%$ and carrier by volume $85 \%$ [7].

To solve complicated problems, the liquidity properties of ferrofluids give an auspicious solution. The various characteristics of ferrofluids, suggest possibilities in applying in devices like micro pumps, bearings and in almost all types of sensors. To create compact and durable devices ferrofluids play an important role. The traditional applications of ferrofluids are in the inclusion of dampers and isolators [8]. Ferrofluid with damping applications a contribution of (Raj) gives exclusive review in 1980's and also Dashpot with linear damper including rotary viscous inertia damper was proposed by Toress-Diaz et al [9] shows an excellent review of latest trends in growing field of ferrofluids which come under the broad category of microfluid(MF) systems.

Recent trends show that ferrofluids based dampers are widely used in areas of single linear vibration[8], [10]. Planar damper technique provides possible solutions for elasticity support which gives drawback instability [6].

In this paper, a novel magnetic absorber with damper structure is proposed and it's characteristics can be used to decrement the external magnetic field and fluid viscosity. Based on the experimental result, the novel structure of a dumb-bell combined with magnetic absorber has produced better result compared with state-of-art techniques. This paper is organized as follows: section 2 describes the concept of the novel magnetic absorber, section 3 , gives the experimental results and the conclusion are derived in section 4 .

\section{A Novel Model of Magnetic Absorber 2.1 Model of Magnetic Absorber}

The second order mass dumb-bell system modeled for novel magnetic absorber and it is expressed in equation 1.

$m \frac{d^{2} r(t)}{d t^{2}}+\frac{c d r(t)}{d t}+k r(t)=-m \frac{d^{2} s(t)}{d t^{2}}$

$\mathrm{m} \rightarrow$ mass of movable permanent magnet

$\mathrm{k} \rightarrow$ stiffness of magnet

$\mathrm{r}(\mathrm{t}) \rightarrow$ relative displacement

$\mathrm{s}(\mathrm{t}) \rightarrow$ external excitation displacement

Revised Manuscript Received on December 05, 2019.

* Correspondence Author

R.Karthick*, Assistant Professor, Department of ECE, Sethu Institute of Technology, Virudhunagar, India, Email: karthickkiwi@gmail.com

P.Meenalochini, Assistant Professor, Department of EEE, Sethu Institute of Technology, Virudhunagar, India, Email: meenalochinip@gmail.com

A.Manoj Prabaharan, Assistant Professor, Department of ECE, Sethu Institute of Technology, Virudhunagar, India, Email: manojprabaharann@gmail.com

P.Selvaprasanth, Assistant Professor, Department of ECE, Sethu Institute of Technology, Virudhunagar, India, Email: selvaprasanth9619@gmail.com Dr.M.Sheik Dawood, Professor, Department of ECE, Sethu Institute of Technology, Virudhunagar, India, Email: sheikdawood7@gmail.com 

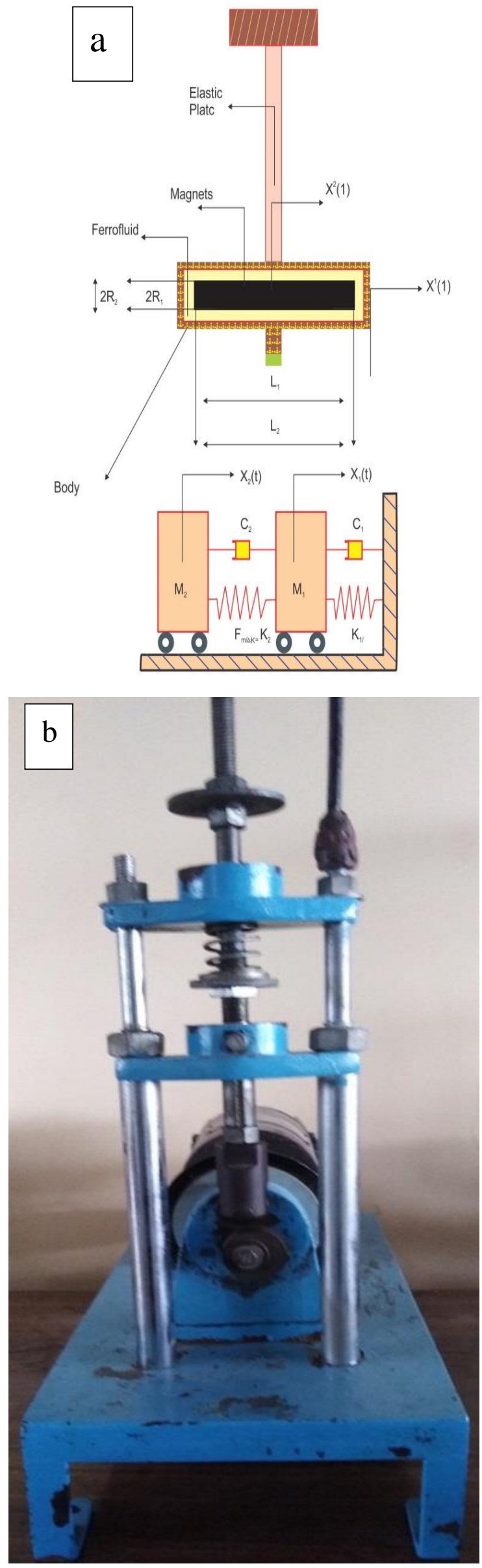

Figure. 1. A scheme of (a) the novel model of the magnetic absorber and (b) the experimental setup.
In stable state condition Permanent Magnet (PM) lies in the inner layer and fixed in axial direction. If any movement occurs, lower region oscillates along with horizontal force $\mathrm{F}$, i.e.

$F=\frac{\mu_{o} Q^{2} r}{4 \pi\left(r^{2}+d^{2}\right)^{\frac{3}{2}}}$

From the above equation, $\mathrm{k}$ is called as constant magnetic stiffness $(\mathrm{k}=\mathrm{F} / \mathrm{r})$ for movable and fixed permanent magnet.

\subsection{Theoretical analysis}

The Ferrofluid magnetic absorber has properties of both magnetic and non-magnetic materials in the cylindrical body. The center of body requires support for stability during vibration. By an external vibration, the magnet moves from initial position due to changes that occur in the body then restoration to the original position.

The elastic plate designed at one end is fixed and other end is open and free, through which we can measure performance parameters of magnetic absorber. The important task of absorber model is made by below assumption
a) Collinear magnetization
b) Steady - state ferrofluid flow
c) Constant temperature
d) Change in viscosity

\subsection{Calculation of magnetic elasticity:}

If no external vibration, the magnetic forces show an equilibrium effect because of symmetrically distributed ferrofluid. The overall restoring force is given by,

$$
\begin{aligned}
& \mathrm{Fm}= \\
& \left.\left.\mu_{\mathrm{o}} \int_{0}^{\mathrm{H}} \mathrm{MdH}\right) \mathrm{nds}+\mathrm{Pm}\right) \mathrm{nds}=\oint\left(\frac{1}{2} \mu_{\mathrm{o}} \mathrm{M}_{\mathrm{n}^{2}}+\right.
\end{aligned}
$$

\section{Whereas,}

$P n=\mu_{0} M_{n^{2}} / 2$ is known that normal magnetic traction and $\mathrm{Pm}=\mu_{\mathrm{o}} \int_{0}^{\mathrm{H}} \mathrm{M} \mathrm{dH}$ is termed as fluid magnetic pressure $\mathrm{n} \rightarrow$ unit vector to the magnetic surface.

In case $\mathrm{Pn}<<\mathrm{Pm}$, it is well known and re-written as

$$
\begin{gathered}
\mathrm{Fm}=\oint \mathrm{P}_{\mathrm{m}} \mathrm{nds}=\oint\left(\mu_{\mathrm{o}} \int_{0}^{\mathrm{H}} \mathrm{MdH}\right) \mathrm{nds} \\
=\mu_{\mathrm{o}} \int \mathrm{M} \nabla \mathrm{Hdv}
\end{gathered}
$$

\section{RESULTS}

The new dumb-bell shape of ferrofluid is present in between the inner layer with magnetic absorber[11],[12],[13]. Due to magneto static force, there is a change in an axial direction of moving permanent magnet. If ferrofluid mass increases the damping co-efficient decreases. The mass of $3.1 \mathrm{~g}$ ferrofluids present on the permanent magnet reaches the saturation state. If the container height decreases from $10 \mathrm{~mm}$ to $8.5 \mathrm{~mm}$ with mass of $3.6 \mathrm{~g}$ ferrofluids, the damping co-efficient raises above 3 times.

In this experiment, the frequency reading noted due to oscillations are $4.2 \mathrm{~Hz}$ and starting amplitude is $6.5 \mathrm{~mm}$. the ferrofluids drop of mass $3.6 \mathrm{~g}$ and an inner layer height 8.5 $\mathrm{mm}$ attained by magnetic absorber. The experimental setup for proposed magnetic 
absorber, the overall system oscillations are unstable. The oscillating time can be minimized by $90 \%$ when weight of ferrofluid is $35 \mathrm{~g}$.

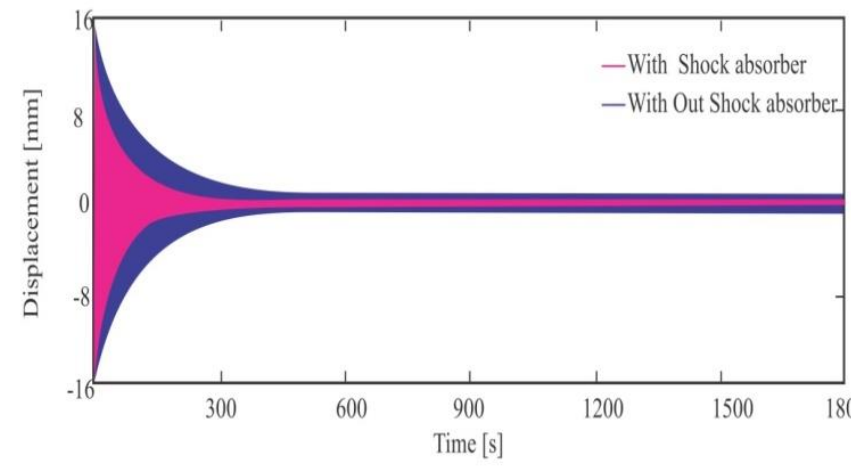

Figure 2.Diagram of beam oscillations (blue) without shock absorber and (pink) with shock absorber.

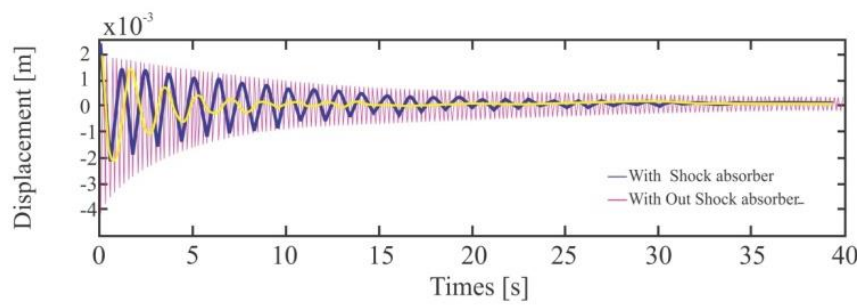

Figure 3. Diagram of ferrofluid damper (pink) without shock absorber (blue) with shock absorber.

Figure. (2) and (3) shows the beam oscillations with and without the damper based magnetic absorber. The optimization of magnetic absorber with the parameters of distance ' $\mathrm{d}$ ' as $30 \mathrm{~mm}$ and radius ' $\mathrm{r}$ ' as $12.5 \mathrm{~mm}$. The oscillating duration is four times smaller in (pink) and (blue).

\section{CONCLUSIONS}

In this paper, a novel ferrofluid damper based magnetic absorber is proposed and the theoretical analyses are made clearly. Some properties of damper based magnetic absorber are analyzed by theoretical as well as practical experimentation. An exclusive device was fabricated and its absorber characteristics were practically measured. According to the experimental values, our system shows improved performance and when external magnetic field is applied and also very susceptible to the attenuation. The system with improvised techniques requires one-third time than a conventional absorber to dissipate the shock. Better performance will be achieved in future and moreover, the magnetic absorber is planned to be put to use in satellite application.

\section{REFERENCES}

1. Karthick, R and Sundararajan, M. (2017), "A Reconfigurable Method for Time Correlated MIMO Channels with a Decision Feedback Receiver," International Journal of Applied Engineering Research, 12 .

2. Karthick, R and Sundararajan, M.(2017), "PSO based out-of-order (ooo) execution scheme for HT-MPSOC" Journal of Advanced Research in Dynamical and Control Systems, 9.

3. Karthick, R and Sundararajan, M. (2017), "Design and Implementation of Low Power Testing Using Advanced Razor Based Processor," International Journal of Applied Engineering Research,12.

4. Karthick, R and Sundararajan, M. (2018),“A novel 3-D-IC tes architecture-a review," International Journal of Engineering and Technology (UAE), 7 .

5. K. Narmashiri, H. T. SMT, Tuned Mass Damper, Lap Lambert Academic Publishing, Germany (2013) pp 1774-1779.

6. R. E. Rosensweig.(1997),Ferro hydrodynamic, Dover Publications, Inc. Mineola, New York

7. S Wang*, Yongkai Liu, and Decai Li, (2018), J.Magn 23(3).

8. R.Karthick, P Selvaprasanth, A Manoj Prabaharan, "Integrated System For Regional Navigator And Seasons Management," Journal of Global Research in Computer Science 9(4),2018(11-15).

9. R.Karthick, N. Sathiyanathan, and M. Eden, "Medical Image Compression Using View Compensated Wavelet Transform” Journal of Global Research in Computer Science 9(9),2018(1-4).

10. 10 Karthick, R and Prabaharan, A.Manoj and Selvaprasanth, P. and Sathiyanathan, N. and Nagaraj, A., High Resolution Image Scaling Using Fuzzy Based FPGA Implementation (March 15, 2019). Asian Journal of Applied Science and Technology (AJAST), Volume 3, Issue 1, Pages 215-221, Jan-March 2019 . Available at SSRN: https://ssrn.com/abstract=3353627

11. Karthick, R and Sundhararajan, M., Hardware Evaluation of Second Round SHA-3 Candidates Using FPGA (April 2, 2014). "International Journal of Advanced Research in Computer Science \& Technology” (IJARCST 2014), Vol. 2, Issue 2, Ver. 3 (April - June 2014). Available at SSRN: https://ssrn.com/abstract=3345417.

12. Karthick, R and and Prabaharan, A.Manoj and Selvaprasanth, P. "Internet of Things based High Security Border Surveillance Strategy" (May 24, 2019). Asian Journal of Applied Science and Technology (AJAST), Volume 3, Issue 2, Pages 94-100, Apr-June 2019. Available at SSRN: https://ssrn.com/abstract= 3394082.

13. Karthick, R and Sundararajan, M: "SPIDER based out-of-order (ooo) execution scheme for HT-MPSOC" International Journal of Advanced Intelligence paradigms, In Press.

14. Karthick, R and John Pragasam, D "Design of Low Power MPSoC Architecture using DR Method" Asian Journal of Applied Science and Technology (AJAST) Volume 3, Issue 2, Pages 101-104, April -June 2019.

\section{AUTHORS PROFILE}

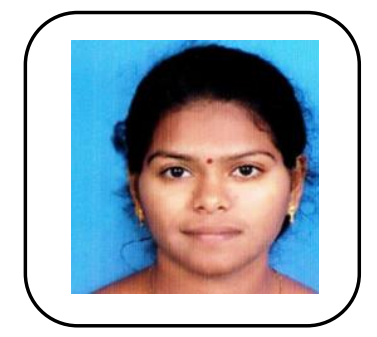

Dr.R.Karthick does research in Electrical Engineering and Communication Engineering. Assistan Professor, Electronics and Communication Engineering, Sethu Institute of Technology, Virudhunagar, Tamil Nadu, India.

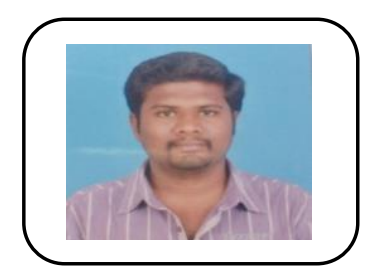

P.Meenalochini does research in Electrical Engineering and Communication Engineering. Assistant Professor, Electrical and Electronics Engineering, Sethu Institute of Technology, Virudhunagar, Tamil Nadu, India

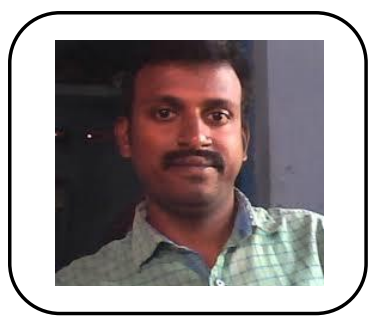

A.Manoj Prabaharan does research in Electrical Engineering and Embedded Systems. Assistant Professor, Electronics and Communication Engineering, Sethu Institute of Technology, Virudhunagar, Tamil Nadu, India. 


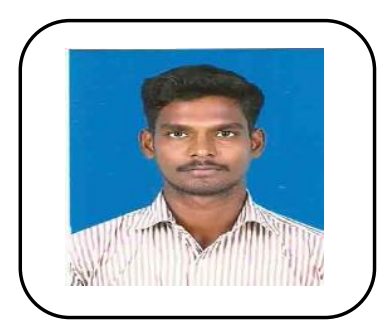

P.Selvaprasanth does research in Applied Electronics. Assistant Professor, Electronics and Communication Engineering, Sethu Institute of Technology, Virudhunagar, Tamil Nadu, India.

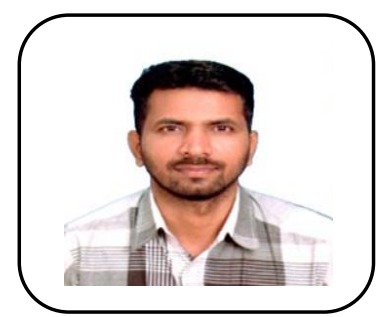

Dr.M.Sheik Dawood does research in Wireless sensor networks. Professor, Electronics and Communication Engineering, Sethu Institute of Technology, Virudhunagar 